\title{
Working Elements of Music Therapy for Children and Young People with Autism
}

\author{
Mathieu Pater ${ }^{(}$, Paula de Graaf, Tom van Yperen \\ Woestijgerweg 49, 3817 SC, Amersfoort, The Netherlands \\ Email: m.pater@stichtingpapageno.nl
}

How to cite this paper: Pater, M., de Graaf, P. and van Yperen, T. (2019) Working Elements of Music Therapy for Children and Young People with Autism. Open Journal of Medical Psychology, 8, 78-96. https://doi.org/10.4236/ojmp.2019.84008

Received: September 6, 2019

Accepted: October 15, 2019

Published: October 18, 2019

Copyright $\odot 2019$ by author(s) and Scientific Research Publishing Inc. This work is licensed under the Creative Commons Attribution International License (CC BY 4.0).

http://creativecommons.org/licenses/by/4.0/

(c) (i) Open Access

\begin{abstract}
Music therapy is used in the treatment of children and young people with autism. Several studies show that it has positive effects, especially in the areas of social behavior and communication. However, there has been no research into which elements are responsible for these effects. This study explores which elements facilitate a change in social behavior. To research this, a combination of the Grounded Theory and the Stimulated Recall Method was used. Therapies with 14 clients were analyzed and the music therapists were interviewed using the Stimulated Recall Method. After the data analysis, five element categories were presented that stimulated a change in social behavior in children and adolescents with autism: Format, Communication, Musical Elements, Connecting and Challenging. Those categories were then incorporated into a first working model, which demonstrates how changes in the social behavior of children and young people with autism occur during the music therapy process. The therapist's continuous adaptation to the client proves to be an important element of this process.
\end{abstract}

\section{Keywords}

Autism, Music Therapy, Effective Elements, Social Behavior

\section{Introduction}

Autism is a qualitative deficit of social and communicative skills. In addition, there are stereotypical behavioral patterns, interests and activities [1] [2] [3]. Autism is often visible in early childhood and has lifelong consequences. Limitations in the ability to communicate and in social interactions are often the most noticeable. This is a permanent limitation that is present in various situations and in different ways [4] [5]. Studies show that children with autism engage in considerably fewer social interactions than children with a normal development 
[6] [7]. As a result, they develop fewer mutual friendships [8]. This limitation also affects the ability to have a conversation, to play together, to feel the perspective and emotions of the other person, and to understand and use gestures and body-posture [9]. People with autism require contextual support at various levels, depending on their capacity for social interaction [1]. However, it seems that these skills are not easy to teach and acquire. Therapists need to be very creative in order to relate to what people with autism are experiencing, because they are very introverted. It is a major challenge to find a suitable treatment method, because people with autism are not easily encouraged to work on these social skills [10]. Social interaction is described as a reciprocal process, in which children take social initiatives and respond to social stimuli of their peers [11]. Music therapy is proposed as an effective approach for teaching social interaction skills. New skills can be taught by using music to adapt to the behavior and interests of the client [12] [13] [14]. Music is used as a motivational stimulus that can facilitate a response in children with autism. Moreover, it provides a clear structure for targeting speech sounds and verbal behavior, and it allows for multiple opportunities to practice social skills within a musical context [15]. In the first studies, social interaction between the therapist and the client through music was considered the most important element of music therapy [16]. In a recent study, Mössler and colleagues [17] showed that the music-therapeutic relationship is an important predictor for the development of social skills, communication and language-specific skills.

Previous studies show that the use of music therapy has a positive effect on the social behavior of children with autism [18]-[26]. In addition, studies show a positive effect on communication skills [18] [19] [24] [27] [28] [29] [30].

However, the studies on this topic performed thus far have their limitations. The intervention and target behavior are often not described adequately, and the question remains whether the correct research methods are being used to study the intervention [31] [32] [33] [34]. Moreover, in a study to assess the methods of music therapists [35], the therapists indicate that they mostly work intuitively to adapt to the needs and capabilities of the target group. On the one hand, they feel it is important to let their work be guided by their feelings and intuition, and on the other hand, they also want well-founded interventions. For these reasons, it is important that the actual effective elements of music therapy are determined.

Various studies have used music therapy based on improvisation [20] [24] [36] [37]. Other studies had a more fixed structure [16] [38], or existing or adapted songs were used [22] [23] [39].

To date, there is no existing research that describes which elements in music therapy are facilitating improvement in the social behavior of children with autism. In the current study, the goal is to explore which elements in music therapy might facilitate a change in social behavior. In addition, this study will describe the first working model of the effective factors in music therapy, focused on the social behavior of children and young people with autism. 


\section{Method}

This qualitative research is part of an ongoing research project. The main goal is to develop an intervention manual and to gain insight into the effect of music therapy on the social behavior of children and adolescents. The project has the following phases: 1) Literature study, in which an inventory is made of the available studies on music therapy, in relation to autism and social behavior. The findings have been published in the article [34]. 2) Development of a practice-based intervention manual. This manual is the starting point for the music therapy, which will be further examined in this study. 3) Qualitative research into the active elements in the intervention. The study presented here pertains to this phase. 4) Research into the effectiveness of the manualized intervention. This is examined in a repeated single case study $(n=40)$.

Research Method

To investigate which elements in music therapy facilitate a change in social behavior, we used the principles of the Grounded Theory [40] [41]. Information from the field was collected bottom-up, to gain insight into the processes that take place in music therapy. These insights help to create a first theoretical working model regarding those elements that facilitate a change when using music therapy in children with autism.

The research uses the "Stimulated Recall Method". This method involves showing a person a recording of himself/herself in a natural setting, a therapy session in this case, and then asking the person to put into words his or her thoughts at the time of the recording [42] [43]. The Stimulated Recall Method focuses on interactive cognition. This refers to the "unconscious" knowledge, thoughts and the resulting actions [44]. During the interview, these are connected to the views, knowledge, ideas, attitudes and skills of the therapist. The Stimulated Recall Method can help provide insight into this, often unconscious process [42] [45], and reveal the motivation behind the actions to the music therapist.

\section{The participants}

We have recorded the treatment of fourteen children and young people with autism, aged 4 to 16 years, in the period mid-2017 to mid-2018, with an autism diagnosis based on the criteria from DSM IV [46] and DSM V [1]. The participating children were between 5 and 16 years old. The average age of the participants is 8.8 years old. Most participants attended a special education school. We did not know the IQ of all participants, but for the participants of whom the IQ was known, it ranged between 70 and 110 .

\section{Participating music therapists}

Seven music therapists were selected from the Papageno foundation network of music therapists on a convenience sampling basis [47]. The therapists were subject to the following inclusion criteria: provide therapy as part of repeated single case study; have completed a music therapy course; be a member of the quality register by the Dutch register for music therapy; have at least two years of experience with the target group. 


\section{The intervention manual}

Music therapy is offered based on an intervention guide written specifically for the study [48]. The intervention is aimed at improving social behavior. The intervention manual consists of 20 individual music therapy sessions, of approximately 40 minutes. The therapist can choose the most suitable work method, based on the client's needs. The selected interventions are recorded in the logbook, the music therapist maintains one for every client. The selection of the work method depends on the needs of the child and the phase of the therapy. The therapy consists of four phases: the intake phase (a pre-therapy session), the observation phase (session 1-6), the treatment phase (session 7-17), the concluding phase (session 18-20). At the beginning of the therapy, the therapist usually offers work methods which follow the client. The therapist is in tune with the tempo and volume of the music and the choices of the client, described in the intervention manual under empathic and structuring methods. Later on, there will be more control, the therapist will create challenges by changing the speed, inserting silences or strongly varying the volume.

Techniques described in the intervention manual are in line with the improvisation techniques of Kenneth Bruscia [49]. The following techniques are used: e.g. empathy techniques, structuring techniques, incitement techniques, techniques for taking back the lead, techniques concerning intimacy, procedural techniques, referral techniques and techniques to examine their emotions.

We also offer structured methods in which the musical parameters and the different aspects that determine the music (sound, rhythm, melody, dynamics and form) [50] are used to facilitate change.

Procedure

In this study, the researchers 1) selected video recordings of therapy sessions, 2) conducted and coded interviews with the therapists, 3) discussed the results with the therapists, and 4) constructed a theoretical model of the working elements.

\section{Step 1: Selection of video fragments}

All therapy sessions were recorded with a video camera. In order to create a complete picture of the interaction during the different phases of the therapy, we selected sessions of every phase of the therapy, to be analyzed by the reviewers. After looking at the video material of two complete therapy trajectories, we concluded that a sample of four sessions (2,8,12 and 18) provides an adequate summary of the whole therapy trajectory process. It gives a good idea of the work methods that were used during the different phases of the therapy process.

The videos were always analyzed by two of the four reviewers: a music therapist and a researcher (1st author); a psychologist and a researcher (2d author); a music therapist; an applied psychology student. To safeguard the intersubjectivity, the analysis was performed by observers with varying professional backgrounds.

The recorded sessions were observed and reported using a video analysis form. This form was used to note down instances of contact between the client 
and the music therapist. When there was a contact moment, the time code of the video was noted on the form. When determining these contact moments, things to consider were the client's reaction, both verbal (spoken text, making noises) and non-verbal (posture, eye contact) as well as musical. Then, the therapist's behavior immediately preceding this contact moment was reviewed. A distinction was made between the therapist's behavior using music or without music.

The video analysis was carried out separately by two reviewers. The observation forms were then compared and used as a basis for a list of video clips. This list served as a guideline for the intensive video analysis interview with the music therapist. If both reviewers made the same observations, this fragment was directly included in the list of clips. If the moment was only observed by one of the reviewers, the fragment was viewed again to agree on whether there was an actual contact moment.

Subsequently, fragments from two of the four analyzed sessions were selected for discussion in the interview. This sample was taken because the Stimulated Recall Method is an intensive and time-consuming method. The choice of therapy sessions was based on the amount of contact moments that were reported, and by taking the overlap in the reported items between the reviewers into consideration. The reviewers and the therapist watched the selected sessions together.

Step 2: Interview

The next step was a semi-structured interview, where the video clips from the list were reviewed with the music therapist. The interviews were done by the researchers, the therapist was invited for the research in a quiet room where the video was watched together. The interviews lasted between 1.5 and 2 hours. The purpose of the interview is to find out why the therapist acted the way he/she did or what caused the behavior of the therapist. The fragment containing the therapist's action and the contact moment were viewed together and discussed using the questions "What happened here?" and "What did you do as therapist?". The therapist's answer was discussed more in depth based using follow-up questions about the therapist's objective and the effects of the action. Audio recordings and transcriptions were made of the interviews.

\section{Data analysis}

The interview was coded individually by the two reviewers. This was done in order to create an objective analysis, both from a music-therapeutic point of view by the music therapist, and from a behavioral point of view by the psychologist. The first step was open coding. During this phase, codes were allocated to parts of text to indicate what they were about. These codes were compared by both reviewers, taking corresponding topics and differences into account. Any differences were discussed to seek agreement. The next step was axial coding. This phase was mainly used to order and compare the codes from the different interviews to find general themes. This process is called "constant comparison". The third and last step was selective coding, where only the most important themes were selected. The cohesion of the themes was analyzed using 
the constant comparisons between the various interviews, the reviewers and the common themes. We interviewed a total of 7 therapists and reviewed therapy sessions for 14 different clients until we reached a saturation point for each item.

Step 3: Feedback

In order to develop a first working model based on the results of the interview, it's important to have a consensus on the results of the interviews. For this reason, the themes that emerged from the selective coding were shared with the respective music therapists during a group interview. This allowed for confirmation of whether the respondents could agree with the results. Also known as, using "member checking" to verify "credibility" [51].

\section{Step 4: Theory Development}

Step 1 focuses on the moments when there was contact between the client and the therapist during the sessions. During step 2, we conducted interviews to see how these contact moments came about. In step 3, a group interview led to a consensus on the findings of elements of the therapy. In step 4, based on these findings, we developed a first working model that aims to explain how music therapy can improve social behavior in children and adolescents with autism. In order to get a consensus on this working model, it was also presented to the therapists who were interviewed at an earlier stage.

\section{Results}

The results will be explained using the various steps of the model development process.

\section{Step 1: Video Analysis}

We watched four sessions for each client. When it showed a contact moment, we reported it along with the time code. Some examples are: at 00:05 the therapist hits the guitar firmly to play the opening song, the client looks at the therapist with a big smile. At 09:35 the client gently rubs the cymbals of the drumkit, the therapist hits it hard. The client looks up at the therapist and waits, when the therapist stops, the client also hits the cymbal. At 20:25 the therapist sang different lyrics "in a fast car, red with black tires ...", the client looked directly at the therapist and corrected the lyrics. On average, we scored about 35 moments for each observed session. These moments provided the input for the interview in which we watched the fragments with the therapist.

\section{Step 2: Interview and data analysis}

The interview and the data analysis were carried out as described in step 2 of the procedure. The analyzed data related to actions or events that caused a contact moment in the music therapy. The data analysis yielded 33 categories in total. The reviewers compared these 33 themes based on content, and clustered them into 5 main categories: Format, Communication, Musical Elements, Connecting and Challenging. For instance, the categories recognizable structure and fixed sequence both link into the organization of the therapy and therefore can both be added to the main category Format. The main categories and sub-categories are displayed in Table 1. 
Table 1. Data analysis categories.

\begin{tabular}{|c|c|c|c|c|}
\hline Format & Communication & Musical elements & Connecting & Challenging \\
\hline Structure & $\begin{array}{c}\text { Verbal } \\
\text { communication }\end{array}$ & Dynamics & $\begin{array}{l}\text { Connecting with } \\
\text { interests }\end{array}$ & Surprise \\
\hline Predictability & $\begin{array}{c}\text { Non-verbal } \\
\text { communication }\end{array}$ & Rhythm & $\begin{array}{c}\text { Engaging in the } \\
\text { moment }\end{array}$ & Instruments \\
\hline $\begin{array}{l}\text { Recognizable } \\
\text { structure }\end{array}$ & $\begin{array}{c}\text { Musical } \\
\text { communication }\end{array}$ & Tempo & Following & Experimenting \\
\hline $\begin{array}{l}\text { Recurring } \\
\text { elements }\end{array}$ & $\begin{array}{l}\text { Combination of } \\
\text { communication styles }\end{array}$ & Volume & Imitating & Exaggerating \\
\hline Fixed sequence & & Timing & Synchronizes & Attributes \\
\hline Melody & & & Initiative & Humor \\
\hline \multirow[t]{2}{*}{ Cadence } & & & Space & Silence \\
\hline & & & Confirming & Instructions \\
\hline
\end{tabular}

The five main categories and their themes will be described here, whereby the 33 themes are in italics in the description.

Format

Creating structure during therapy is done to give the client a feeling of control and predictability. The therapist ensures a recognizable structure, both during the sessions and throughout the overall therapy. This is achieved by incorporating recurring elements, such as an opening song or a fixed sequence of methods.

The therapist provides a clear structure for the therapy session, but within this structure, the therapist makes room for the client's own input. The therapist tries to integrate this input within the structure of the therapy by adapting and creating boundaries.

An example of a therapy session: Every session starts with an opening song that welcomes both the client and the therapist: "Hello John, it's Tuesday and we're going to make some music...”. Then the therapist explains the work method to the client, sometimes with a recurring instrument and sometimes with a new instrument. After work methods with instruments, they always sing songs together, chosen by the child from a folder. The song is repeated two or three times and then the child chooses a new song. The session always ends with the final song: "Goodbye John, goodbye John, we are finished for today...".

The inclusion of a melody or cadence is used to create structure in the child's play. This is often used as a means to return to the structure of the session. An example: the therapist played a rhythm of "do ta ta ch, do ta ta ch, TA TA TA TA, do ta ta ch". The therapist puts the accent on the "TA TA TA TA" which draws the attention of the child who is distracted. When the client notices this and is alert again, they can continue where they left off.

Communication

The therapy includes the use of various methods of communication to make contact with the client. These are verbal communication, non-verbal communication and communication via music or a combination thereof.

Verbal communication is often used to describe or confirm what is happen- 
ing. But it is also practical to invite, or to explain a working method or the course of the therapy. Non-verbal communication used by the therapist includes posture, eye contact, facial expression, physical distance and physical contact. During the session, the therapist uses eye contact when she changes the tempo in a song, to see if there is joint attention. This way of communicating is used to invite and connect. For example, the therapist may initiate a connection by making his/her body small, bending over the guitar and playing it softly. Then, the therapist could carefully advance and once there is contact, start to sit up more and play increasingly louder. This allows the therapist to support his/her play with posture and body language. Physical contact in young children is also initiated by holding a hand, for instance, and inviting the child.

A third communication method is musical communication. This is where music is used as the medium of communication. The versatility of the musical elements and the possible variations offer many opportunities.

By combining the different ways of communication, the effect is enhanced. When the therapist asks a question verbally, he or she can support this further by adapting posture and facial expressions to the question. Since the different communication methods play into one another, they create an overall effect, which clarifies the message.

\section{Musical elements}

Since the study is aimed at music therapy, much of the conversation in the interviews was about music. The role of music in each situation was considered during coding. The main category "musical elements" describes how music is specifically used for adaptation. The elements dynamics, volume, rhythm and tempo can be adjusted to what the child is doing or to challenge other behavior. Volume is about the sound strength of the music, loud and soft and everything in between. Dynamics refers to the transitions from hard to soft or vice versa. Rhythm are the musical patterns in time, the short and long tones in the time. These can be varied, and accents can be shifted in unexpected ways. The tempo is the speed with which music is performed, which can be fast (high tempo) or slow (low tempo) for example. There can also be tempo changes in which the music is slowed down or accelerated. In music therapy, the therapist plays with these elements by alternating them and thus activating the child. The therapist can make very predictable changes, but also unexpected ones. An example of this is when a therapist abruptly stops during a song and drops a silence. The therapists play with timing to make it easier for the child to take the initiative. For example, the therapist drops a silence so that the child can fill this silence by making a sound. By adding an unexpected moment of silence, the child is encouraged to react.

\section{Connection}

The interviews show that the therapists seek a connection in order to make contact with the client. This category describes the methods most mentioned by therapists as being used for connecting with the client.

The therapist connects with the interests of the client by using topics, themes 
or musical instruments that he/she knows appeal to the client. For example, one music therapy client was fascinated with teacups. The therapist used this fascination by incorporating it in songs. By using his fascination, the child was very motivated to participate. The therapist also uses situations that occur during the session as input for a method. By engaging in the moment, the therapist connects with whatever the client is doing about at that moment, and therefore ensures shared attention. Another way of connecting is when the therapist follows, imitates or synchronizes. It makes the client aware of his/her own actions and it also encourages the client to take more initiative. When imitating, the therapist copies exactly what the client plays, in melody, volume and tempo. As the client often needs some more time to process an exercise or task, the therapist will sometimes make room for this on purpose. An example is waiting or slowing down the music. A therapist may also choose to let a client do his or her own thing for a little while. The therapist may also establish a connection by confirming what the client is doing. This can be done in several ways, for instance by going along with the client's behavior or by reacting positively to this behavior.

\section{Challenging}

The client is stimulated to exhibit different behavior when a change is made or something new is added to the music therapy. The therapist uses unpredictability, a surprise, to elicit a reaction or change. This may be a surprise in the music, such as a sudden change of tempo. New instruments can be used to pique curiosity. The therapist can also use instruments in a different, experimental way to trigger inquisitive behavior and thinking outside the box. Examples of this could be using the guitar as a drum or singing into the bottom of a djembe. In order to provoke a reaction, the therapist can mirror an exaggeration of the client's behavior or exaggerate one of their own actions. The exaggeration could be in posture, voice volume and/or instruments.

Attributes, such as an umbrella, are sometimes used as props to motivate a client while following a method. The therapist attracts attention by using a silly voice or sound. Using humor elicits spontaneity. This could also be achieved with improvised songs with "silly" words, or by changing an existing song. During music therapy, the therapist consciously uses silence to capture the client's attention. This literally gives the client space too, to let himself or herself be heard. For example, when the therapist suddenly falls silent during a song, the client is challenged to fill in the appropriate sentence or word. To teach the client new skills, the therapist gives instructions, or demonstrates what is expected.

\section{Step 3: Feedback}

The 33 subcategories were discussed in a group interview with the music therapists and a concept of the model was presented. The therapists were asked if they agreed with the categories. They were also asked if, in their experience, these categories contribute to the therapy results. We then looked at whether the therapists agreed with the five main categories. The main categories and the 
classification of the subcategories were unanimously recognized and confirmed by the therapists.

The concept was also presented during the group interview, which will be presented further along in this article as the "Working Elements Model".

The participants were asked if they agreed with the categories and the model, which all did. But in the discussion two essential elements came forward thataccording to the participants-were missing. The first is Therapeutic setting. The therapy takes place somewhere, and the requirements this space has to meet also seem important to the therapy. The discussion of this element further showed that a distinction can be made between this therapeutic setting on the one hand, which forms a predictable foundation of the therapy, and the therapeutic process on the other, which is characterized by a continuous interplay between the therapist and the client, and in which elements of connecting and challenging play their role. This interplay in the process was mentioned as the second missing element and was labeled Adaptation. During music therapy, the therapist constantly observes and interprets the behavior and emotions of the child, trying to find a balance between connecting and challenging with him or her.

\section{Step 4: Working Elements Model}

Based on the data analysis and the discussion, a first working model was created of the working factors in this form of music therapy that used an intervention manual and that was aimed at improving the social behavior of children and young people with autism (Figure 1).

The model contains the elements "therapeutic setting", "therapeutic process" and "music". These are explained below.

\section{Therapeutic setting:}

The therapeutic setting forms the basis for the therapy, to work towards the objective.

\section{Basic requirements}

To create a safe working environment, it is good to take a number of aspects into consideration. It has a strong preference that the therapy takes place at a fixed time, in the same space. This space should be peaceful and uncluttered, whereby the sounds and music are not disruptive to the environment and vice versa.

\section{Format}

As described above, the music therapy has a fixed format that creates structure and predictability. This is important for the specific target group to experience the right level of safety.

\section{Therapist}

The therapist should be a predictable and safe person to the client. Each music therapist has his or her own style, which allows for an authentic relationship to develop between the therapist and the client. The therapist has various methods and music instruments at his or her disposal to establish contact, which are the previously mentioned verbal, non-verbal and musical ways of communicating. 


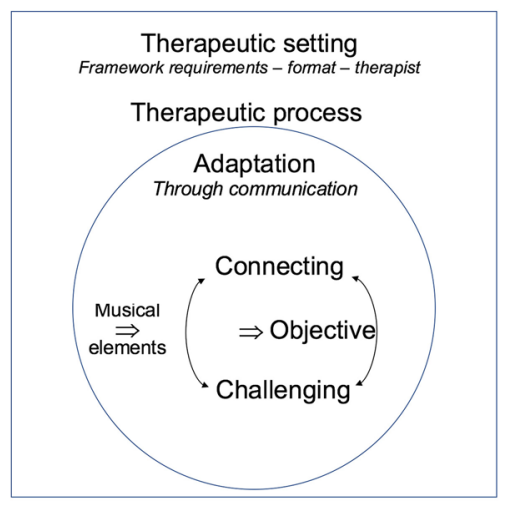

Figure 1. Working elements in music therapy.

\section{Therapeutic process:}

The interaction between the therapist and the client takes place within the therapeutic process. This process serves to work towards the therapeutic objectives. An important condition here is the communication and the connection between the therapist and the client. In the interaction, the therapist can encourage new behavior by first connecting with the client and challenging him or her.

\section{Adaptation:}

As mentioned before, during music therapy, the therapist constantly observes the client. This includes looking at the client's concentration, energy level, reaction, behavior and facial expression. The therapist adopts a flexible attitude, balancing between following and guiding. This is a continuous process whereby the therapist adapts his or her behavior to the client. The way in which he or she communicates is an important element used by the music therapist to adapt to the client. The therapist uses verbal communication, non-verbal communication and musical communication.

\section{Connecting and challenging.}

In order to stimulate the client to adapt a new behavior, the therapist connects with the client. When the connection is established, the therapist can encourage the client to try something new. Connecting and challenging are closely linked. When challenging, the therapist maintains the connection with the client and tries to move the client's boundaries while still connected. The moment the focus is on challenging, the therapist will keep adapting to the client and can decide at any time to shift the focus back to connecting when it becomes apparent that he or she is "losing" the connection with the client. This is a continuous dynamic process. The therapist attempts to take one more step each time when challenging and to stimulate the client towards new behavior to achieve the objective.

Change takes place when the therapist succeeds in pushing the client's boundaries by challenging the child, so that the new behavior can be practiced. Initially, these are often short moments of challenge. During the course of the therapy, the balance of connecting and challenging moves more towards the 
challenge aspect. In this way the social behavior of the client is trained with the client comfortable enough to make the new behavior his/her own.

The moments the therapist can challenge the client are brief. As soon as there is too much tension or stress, the client will pull away. This is why it is so important to keep adapting to the client and to connect again when necessary. The therapist continuously assesses the level of involvement: is it sufficient to take another step and can the focus be placed on challenging, or should the therapist attempt to find connection first?

\section{Music:}

Music is present in therapy in many different ways. It plays a role in all areas of the model for working elements during music therapy. Music is used in the therapeutic setting to create the format and it is the most important communication medium the therapist has. The therapeutic process utilizes musical elements for adapting, connecting and challenging.

Music can be present to a greater or lesser extent during music therapy. The therapist decides, through adaptation to the client, which role music should play at any given moment. The versatile characteristics of music make it a suitable medium for working with children and young people with autism. It offers the possibility to move and change quickly, both within and between the various musical elements. It allows the therapist to adapt to the client quickly and to vary between connecting and challenging. Music is a very flexible medium. One example is when the therapist and the client play a djembe together. The therapist can adapt to the client by playing the same rhythm as the client, using the same volume, tempo and rhythm. When the client notices this adaptation, the therapist and the client are connected. In order to then encourage and challenge the client to take on new skills, the therapist could for instance play a strong variation in volume. When the therapist notices that this variation is too extreme for the client and that the connection is dwindling, the therapist can transform the strong variation once again to the level where the connection was established.

As described, music is present to a greater or lesser extent in all aspects of the therapy. Sometimes the therapist needs to use more words to explain something to the client. However, clients often pay more attention when the words of the therapist are supported by a song or when the therapist demonstrates what he or she means with an instrument. The way in which music is utilized significantly influences the progress of the therapy and is therefore an important element, contributing to the achievement of the objectives.

\section{Generalization}

Knowing that it is difficult to encourage children and young people with autism to improve their social behavior [10], we have described a first working model of the therapeutic process, which aims for this improvement. The model describes how goals are attained within the therapy. For the therapy to really have an impact, it is important that the social behavior also improves in the 
client's daily life. A hypothesis on the generalization of skills acquired during music therapy is that the therapist does not teach the client any "tricks" for coping with social situations. Instead the therapist encourages him or her to learn a new behavior in a natural and familiar way, by adapting to the client and by alternating between connecting and challenging, and by utilizing the medium of music in different ways. It coaxes the client to try new behavior and allows ample practice so that it can become second nature. By constantly switching between connecting and challenging, the therapist is able to keep moving the behavior, and it allows the client to practice the behavior in various situations at the same time.

Communication can be practiced well during music therapy because it is not necessary to empathize directly with the other person-something that is difficult for people with autism [10] —when making music together [52]. In addition, music therapy is a form of treatment that is well-received at a young age. Treatment of autism in early life is effective and has a sustainable effect [53]. Social interaction is a reciprocal process in which children take social initiative and respond to social stimuli of their peers [11], this process can be practiced through repetition within music therapy.

Taking turns and being able to adapt, are important skills that are needed during contact and communication with another person. The therapist practices this with the client, for instance by playing the djembe together. First the therapist will ask the client to copy what he or she is playing. For example, the therapist plays "DO DO TA DO DO TA" the client repeats this "DO DO TA DO DO TA". When the client repeats this correctly, the therapist affirms this by giving a compliment and continues with a new rhythm. In this way, the client learns how to take turns and adapt when playing a djembe. Since it is difficult for people with autism to generalize, the music therapist challenges the same behavior during other methods, such as while improvising on the piano. The client then learns the same skills on another instrument, in a different context. This example shows how the client is made more and more aware of the right way to take turns and adapt in different situations.

When communicating with another person, one can only fully understand the message when the listener and the speaker are completely connected to each other [54]. Because connecting with others is difficult for people with autism, this is practiced in different ways and at different times during therapy, to make sure that the client starts to better recognize this behavior during therapy. By constant affirmation of the client's target behavior, and by practicing it in different ways, in different situations and at different times, the probability of generalization is increased. In addition, the music therapy takes place at the client's home or at school. By having the therapy take place in this safe environment and making it possible to involve parents (or teachers) in the music therapy, a better generalization of the learned skills is ensured. The description given here is an assumption of how the generalization can take place and it must be further confirmed by research. 


\section{Discussion and Conclusions}

In this study, we investigated which element in music therapy facilitates a change in social behavior of children and adolescents with autism. We also described these findings in a first working model. Based on the interviews, five main categories could be distinguished that seemed important in facilitating a change in social behavior with music therapy. The five categories: format, communication, musical elements, connecting and challenging are used in music therapy to achieve a change in social behavior. During the music therapy session, the therapist constantly adapts to the client. Once they have a connection, the therapist can challenge the client to show different behavior. Connection seems to be an important condition for achieving a change; it ensures the client's attention and motivation to learn a new behavior.

For a music therapist, it can be difficult to translate the process of the therapy into words, since a large part of it occurs at an experiential level. In music therapy, the therapist often responds to the client's actual experiences. Smeijsters [55] poses that an external reviewer could come to observations of this process, compared to those of the practitioner. This is why the interview in this study was conducted using video recordings. It enabled constant verification of the observations and interpretations made by the external reviewer using the input of the therapists.

Overview studies do show that positive effects can be observed in people with autism who received music therapy. [31] [32] [34] [56] [57] [58] [59]. However, there is no existing research into the elements in music therapy that facilitate improvement in the social behavior of children with autism. This study has taken a first step in this direction.

This study has produced an initial work model that describes what the participating music therapists consider to be the working elements in a therapy that aims to improve the social behavior of children and young people with autism. In practice, it often seems difficult for music therapists to express what is really happening during the therapy. In an earlier study, music therapists told the researchers that they mostly work intuitively and that they seem to connect naturally and that they need to adapt to the needs and possibilities of the client [35]. Through interviews in combination with video fragments, it becomes clear what music therapists do and why [51] [60]. Through this method, clinical knowledge and experiences were used "bottom up" for the development of the model [37] [55] [61]. This "bottom up" method was necessary, because literature does not provide insights into the mechanisms responsible for the effects of the therapy, and often does not properly indicate the format of the music therapy [31] [32] [34]. The use of intensive video analysis helps the therapists to articulate their experiences and methods used in practical situations, and therefore provides insight into what is actually happening during the music therapy.

An important note to be made in this study is that the music therapy program that was researched made use of the previously described intervention manual. 
This enables music therapists to offer a uniform therapy, making the results more measurable, and providing insight into what happens during treatment. In our study, we aimed for highlighting the working elements in the treatment, based on observation, theory and discussion. The empirical effect of the therapy and the contribution of each element to this effect have not been subject in this study. This means that we can only hypothesize that we identified working elements; whether or not these elements are really "working" has yet to be determined in future research.

Although music is central in this type of therapy, this study also raises some questions about the exact role it plays. The observations and interviews show that music is present in therapy in many different ways. This increasingly, during the study, raises the question about what "music" exactly is, and what role and function it has in music therapy in its present form. Specific research on this role is recommended.

\section{Ethical Approval}

This research file has been submitted to the secretariat of the Regional Committee for Patient Research (RTPO). They assessed whether the research file should be evaluated according to the Medical Research with Human Subjects Act (WMO). The RTPO concludes that the research does not fall within the scope of the WMO. This is an observational study, using questionnaires for the parents and video recordings of the children.

\section{Conflicts of Interest}

The author declares no conflicts of interest regarding the publication of this paper.

\section{References}

[1] APA (2013) Diagnostic and Statistical Manual of Mental Disorders-DSM-5, 5th Edition, American Psychiatric Publishing, Washington DC.

[2] De Bildt, A.A., Blijd-Hoogerwijs, E.M.A., Dijkstra, S.P., Huizinga, P., Ketelaars, C.E.J., Kraijer, D.W. and Minderaa, R.B. (2007) Pervasieve ontwikkelingsstoornissen. In: Verheij, F., Verhulst, F.C. and Ferdinand, R.F., Eds., Kinder-en jeugdpsychiatrie, behandeling en begeleiding, Van Gorcum, Assen.

[3] Doreleijers, T., Boer, F., Huisman, J., Vermeiren, R. and De Haan, E. (2006) Leerboek psychiatrie, kinderen en adolescenten (Handbook of Psychiatry, Children and Adolescents). De Tijdstroom, Utrecht.

[4] Wing, L. (1997) The Autistic Spectrum. The Lancet, 350, 1761-1766. https://doi.org/10.1016/S0140-6736(97)09218-0

[5] Wing, L. (2001) The Autistic Spectrum: A Parents' Guide to Understanding and Helping Your Child. Ulysses, Berkeley, CA.

[6] Bauminger, N., Shulman, C. and Agam, G. (2003) Peer Interaction and Loneliness in High-Functioning Children with Autism. Journal of Autism and Developmental Disorders, 33, 489-507. https://doi.org/10.1023/A:1025827427901 
[7] Humphrey, N. and Symes, W. (2011) Peer Interaction Patterns among Adolescents with Autistic Spectrum Disorders (ASD's) in Mainstream School Settings. Autism, 15, 397. https://doi.org/10.1177/1362361310387804

[8] Kasari, C., Locke, J., Gulsrud, A. and Rotherham-Fuller, E. (2011) Social Network and Friendships at School: Comparing Children with and without ASD. Journal of Autism and developmental Disorders, 41, 533-544. https://doi.org/10.1007/s10803-010-1076-x

[9] Krasny, L., Williams, B.J., Provencal, S. and Ozonoff, S. (2003) Social Skills Interventions for the Autism Spectrum: Essential Ingredients and a Model Curriculum. Child and Adolescent Psychiatric Clinics in North America, 12, 107-122. https://doi.org/10.1016/S1056-4993(02)00051-2

[10] Schertz, H.H. and Odom, S.L. (2007) Promoting Joint Attention in Toddlers with Autism: A Parentmediated Developmental Model. Journal of Autism and Developmental Disorders, 37, 1562-1575. https://doi.org/10.1007/s10803-006-0290-Z

[11] Shores, R.L. (1987) Overview of Research on Social Interaction: A Historical and Personal Perspective. Behavioral Disorders, 12, 233-241. https://doi.org/10.1177/019874298701200408

[12] Carpente, J. (2016) Investigating the Effectiveness of a Developmental, Individual Difference, Relationship-Based (Dir) Improvisational Music Therapy Program on Social Communication For children with Autism Spectrum Disorder. Music Therapy Perspectives, 35, 160-174. https://doi.org/10.1093/mtp/miw013

[13] Geretsegger, M., Holck, U., Carpente, J., Elefant, C., Kim, J. and Gold, C. (2015) Common Characteristics of Improvisational Approaches in Music Therapy for Children with Autism Spectrum Disorder: Developing Treatment Guidelines. Journal of Music Therapy, 52, 258-281. https://doi.org/10.1093/jmt/thv005

[14] Mössler, K., Gilbertson, S., Krüger, V. and Schmid, W. (2013) Converging Reflections on Music Therapy with Children and Adolescents: A Collaborative Seminar on Diverse Areas of Music Therapy Practice and Research. Voices. A World Forum for Music Therapy, 13. https://doi.org/10.15845/voices.v13i2.721

[15] Adamek, M.S., Thaut, M.H. and Furman, A.G. (2008) Individuals with Autism and Autism Spectrum Disorders (ASD) In: Davis, W.B., Geller, K.E. and Thaut, M.H., Eds., An Introduction to Music Therapy: Theory and Practice, 3rd Edition, American Music Therapy Association, Silver Spring, MD, 117-142.

[16] Arezina, C.H. (2011) The Effect of Interactive Music Therapy on Joint Attention Skills in Preschool Children with Autism Spectrum Disorder. Master's Thesis, University of Kansas, Lawrence, KS.

[17] Mössler, K., Gold, C., Aßmus, J., et al. (2017) The Therapeutic Relationship as Predictor of Change in Music Therapy with Young Children with Autism Spectrum Disorder. Journal of Autism and Developmental Disorders, 49, 2795-2809. https://doi.org/10.1007/s10803-017-3306-y

[18] Edgerton, C.L. (1994) The Effect of Improvisational Music Therapy on the Communicative Behaviors of Autistic Children. Journal of Music Therapy, 31, 31-62. https://doi.org/10.1093/jmt/31.1.31

[19] Gattino, G.S., Riesgo, R.D.S., Longo, D., Leite, J.C.L. and Faccini, L.S. (2011) Effects of Relational Music Therapy on Communication of Children with Autism: A Randomized Controlled Study. Nordic Journal of Music Therapy, 20, 142-154. https://doi.org/10.1080/08098131.2011.566933

[20] Ghasemtabar, S.N., Hosseini, M., Fayyaz, I., Arab, S., Naghashian, H. and Poudineh, Z. (2015) Music Therapy: An Effective Approach in Improving Social Skills of Chil- 
dren with Autism. Advanced Biomedical Research, 4, 157. https://doi.org/10.4103/2277-9175.161584

[21] Katagiri, J. (2009) The Effect of Background Music and Song Texts on the Emotional Understanding of Children with Autism. Journal of Music Therapy, 46, 15-31. https://doi.org/10.1093/jmt/46.1.15

[22] Kern, P. and Aldridge, D. (2006) Using Embedded Music Therapy Interventions to Support Outdoor Play of Young Children with Autism in an Inclusive Community-Based Child Care Program. Journal of Music Therapy, 43, 270-294. https://doi.org/10.1093/jmt/43.4.270

[23] Kern, P., Wolery, M. and Aldridge, D. (2007) Use of Songs to Promote Independence in Morning Greeting Routines for Young Children with Autism. Journal of Autism and Developmental Disorders, 37, 1264-1271.

https://doi.org/10.1007/s10803-006-0272-1

[24] Kim, J., Wigram, T. and Gold, C. (2008) The Effects of Improvisational Music Therapy on Joint Attention behaviours in Autistic Children: A Randomized Controlled Study. Journal of Autism and Developmental Disorders, 38, 1758-1766. https://doi.org/10.1007/s10803-008-0566-6

[25] Vaiouli, P., Grimmet, K. and Ruich, L. (2015) "Bill Is Now Singing": Joint Engagement and the Emergence of Social Communication of Three Young Children with Autism. Autism, 19, 73-83. https://doi.org/10.1177/1362361313511709

[26] Wimpory, D., Chadwick, P. and Nash, S. (1995) Brief Report: Musical Interaction Therapy for Children with Autism: An Evaluative Case Study with Two-Year Follow-up. Journal of Autism and Developmental Disorders, 25, 541-552. https://doi.org/10.1007/BF02178299

[27] Aldridge, D., Gustorff, D. and Neugebauer, L. (1995) A Preliminary Study of Creative Music Therapy in the Treatment of Children with Developmental Delay. The Arts in Psychotherapy, 21, 189-205. https://doi.org/10.1016/0197-4556(95)00019-2

[28] Buday, E.M. (1995) The Effects of Signed and Spoken Words Taught with Music on Sign and Speech Imitation by Children with Autism. Journal of Music Therapy, 32, 189-202. https://doi.org/10.1016/0197-4556(95)00019-2

[29] Farmer K.J. (2003) The Effect of Music vs. Nonmusic Paired with Gestures on Spontaneous Verbal and Nonverbal Communication Skills of Children with Autism Ages 1-5. Master's Thesis, Florida State University, Tallahassee, FL.

[30] Thompson, G.A., McFerran, K.S. and Gold, C. (2013) Family-Centred Music Therapy to Promote Social Engagement in Young Children with Severe Autism Spectrum Disorder: A Randomized Controlled Study. Child: Care, Health and Development, 40, 840-852. https://doi.org/10.1111/cch.12121

[31] Accordino, R., Comer, R. and Heller, W.B. (2007) Searching for Music's Potential: A Critical Examination of Research on Music Therapy with Individuals with Autism. Research in Autism Spectrum Disorders, 1, 101-115. https://doi.org/10.1016/j.rasd.2006.08.002

[32] Geretsegger, M., Elefant, C., Mössler, K. and Gold, C. (2014) Music Therapy for People with Autism Spectrum Disorder. The Cochrane Database of Systematic Reviews. https://doi.org/10.1002/14651858.CD004381.pub3

[33] Kaplan, R.S. and Steele, A.L. (2005) An Analysis of Music Therapy Program Goals and Outcomes for Clients with Diagnoses of the Autism Spectrum. Journal of Music Therapy, 42, 2-19. https://doi.org/10.1093/jmt/42.1.2

[34] Pater, M. and van Yperen, T. (2017) Muziektherapie voor kinderen en jongeren met ASS: En overzicht van de relevante literatuur. Kind en Adolescent, 38, 233-259. 
https://doi.org/10.1007/s12453-017-0156-5

[35] Pater, M.L.A. (2016) Praktijkonderzoek naar de inzet van muziektherapie bij kinderen en jongeren met ASS. Stichting Papageno, Laren.

[36] Dezfoolian, L., Zarei, M., Ashayri, H. and Looyeh, M.Y. (2013) A Pilot Study on the Effects of Orff-Based Therapeutic Music in Children with Autism Spectrum Disorder. Music and Medicine, 5, 162-168. https://doi.org/10.1177/1943862113491502

[37] Van Yperen, T.A. and Veerman, J.W. (2008) Zicht op effectiviteit. Handboek voor praktijkgestuurd effectonderzoek in de jeugdzorg. Eburon, Delft, The Netherlands.

[38] La Gasse, A.B. (2014) Effects of a Music Therapy Group Intervention on Enhancing Social Skills in Children with Autism. Journal of Music Therapy, 51, 250-275. https://doi.org/10.1093/jmt/thu012

[39] Thomas, A. and Hunter, B. (2003) The Effect of Music Therapy on Communication Skills of Children Ages 2-3 with Autism: A Pilot Study. Proceedings of the American Music Therapy Association Conference, Minneapolis, MN.

[40] Strauss, A. and Corbin, J. (1998) Basics of Qualitative Research Techniques and Procedures for Developing Grounded Theory. 2nd Edition, Sage, London.

[41] Charmaz, K. (2006) Constructing Grounded Theory: A Practical Guide through Qualitative Analysis. Sage, London.

[42] Glass, S.M. and Mackey, A. (2000) Stimulated Recall Methodology in Second Language Research. Routledge, Mahwah, NJ.

[43] Lyle, J. (2003) Stimulated Recall: A Report on Its Use in Naturalistic Research. British Educational Research Journal, 29, 861-878.

https://doi.org/10.1080/0141192032000137349

[44] Hennissen, P., Crasborn, F., Brouwer, N., Korthagen, F. and Bergen, T. (2010) Uncovering Contents of Mentor Teachers' Interactive Cognitions during Mentoring Dialogues. Teaching and Teacher Education, 26, 207-214. https://doi.org/10.1016/j.tate.2009.02.022

[45] Crasborn, F.J.A.J. and Hennissen, P.P.M. (2010) The Skilled Mentor: Mentor Teachers' Use and Acquisition of Supervisory Skills Eindhoven. Technische Universiteit Eindhoven, Eindhoven, Netherlands.

[46] APA (2000) Diagnostic and Statistical Manual of Mental Disorders (DSM-IV TR). American Psychiatric Association, Washington DC.

[47] Bornstein, M.H., Jager, J. and Putnick, D.L. (2013) Sampling in Developmental Science: Situations, Shortcomings, Solutions, and Standards. Developmental Review, 33, 357-370. https://doi.org/10.1016/j.dr.2013.08.003

[48] Pater, M.L.A. (2017) Interventiewijzer, muziektherapie bij kinderen en jongeren met autisme. Stichting Papageno, Laren.

https://doi.org/10.1007/s12453-017-0156-5

[49] Bruscia, K. (1987) Improvisational Models of Music Therapy. Charles C. Thomas, Springfield.

[50] Hegi, F. (1996) Komponenten. In: Decker-Voigt, H.H., Knill, P.J. and Weyemann, E., Eds., Lexikon Musiktherapie, Hogrefe, Gottingen.

[51] Baarda, B. \& de Goede, M. (2005) Basisboek kwalitatief onderzoek. Stenfert Kroese Groningen.

[52] Caria, A., Venuti, P. and de Fasco, S. (2011) Functional and Dysfunctional Brain Circuits Underlying Emotional Processing of Music in Autism Spectrum Disorders. Cerebral Cortex, 21, 2838-2849. https://doi.org/10.1093/cercor/bhr084 
[53] Pickles, A., Le Couteur, A., Leadbitter, K., Salomone, E., Cole-Fletcher, R., Tobin, H., et al. (2016) Parent-Mediated Social Communication Therapy for Young Children with Autism (PACT): Long-Term Follow-up of a Randomized Controlled Trail. The Lancet, 388, 2501-2509. https://doi.org/10.1016/S0140-6736(16)31229-6

[54] Wan, C., Demaine, K., Zipse, L., Norton, A. and Schlaug, G. (2010) From Music Making to Speaking: Engaging the Mirror Neuron System in Autism. Brain Research Bulletin, 82, 161-168. https://doi.org/10.1016/j.brainresbull.2010.04.010

[55] Smeijsters, H. (2006) Handboek Muziektherapie. Bohn Stafleu van Loghum Houten. https://doi.org/10.1007/978-90-313-9685-6

[56] Reschke-Hernández, A.E. (2011) History of Music Therapy Treatment Interventions for Children with Autism. Journal of Music Therapy, 48, 169-207. https://doi.org/10.1093/jmt/48.2.169

[57] Simpson, K. and Keen, D. (2011) Music Interventions for Children with Autism: Narrative Review of the Literature. Journal of Autism and Developmental Disorders, 41, 1507-1514. https://doi.org/10.1007/s10803-010-1172-y

[58] Whipple, J. (2004) Music in Intervention for Children and Adolescent with Autism: A Meta-Analysis. Journal of Music Therapy, 41, 90-106.

https://doi.org/10.1093/jmt/41.2.90

[59] Wigram, T. and Gold, C. (2006) Music Therapy in the Assessment and Treatment of Autistic Spectrum Disorder: Clinical Application and Research Evidence. Child: Care, Health and Development, 32, 535-542. https://doi.org/10.1111/j.1365-2214.2006.00615.x

[60] Migchelbrink, F. (2003) Praktijkgericht onderzoek in zorg en welzijn. Uitgeverij SWP, Amsterdam.

[61] Smeijsters, H. (2008) Handboek creatieve therapie. Coutinho, Bussum. 